Inovação e juventude: um estudo sobre produção e consumo de notícias e o Jornalismo porvir

INNOVATION AND YOUTH: A STUDY ON PRODUCTION AND CONSUMPTION OF NEWS AND THE INCOMING JOURNALISM

\title{
Beatriz Becker
}

Professora Associada do Programa de Pós-Graduação em Comunicação e Cultura e do

Departamento de Expressões e Linguagens da Escola de Comunicação da Universidade Federal do Rio de Janeiro (PPGCOM/ECO-UFRJ). Bolsista de Produtividade em Pesquisa do CNPq. Líder do Grupo de Pesquisa Mídia, Jornalismo Audiovisual e Educação. Realizou o PósDoutorado na Pontifícia Universidade Católica de São Paulo e na Goldsmiths, University of London. É autora de Televisão e Telejornalismo: Transições; A linguagem do Telejornal; Pensando e Fazendo Jornalismo Audiovisual e coautora de Pantanal: A Reinvenção da Telenovela.

E-mail: beatrizbecker@uol.com.br

\section{Igor Waltz}

Jornalista, mestre e doutorando em Comunicação e Cultura pela PPGCOM/ECO/UFRJ. Bolsista PROEX/Capes.

E-mail: igor.waltz2@gmail.com

\section{Heitor Leal Machado}

Mestre e Doutorando em Comunicação e Cultura pelo PPGCOM/ECO/UFRJ.

E-mail: heitorlmachado@gmail.com

\section{Rafael Pereira da Silva}

Jornalista, especialista em Comunicação Empresarial, e mestre em Comunicação e Sociedade pelo PPGCOM/UFJF. Doutorando em Comunicação e Cultura pela PPGCOM/UFRJ. Bolsista Capes.

E-mail: domrafasil@gmail.com 


\section{Resumo}

Refletir sobre o jornalismo porvir implica pensar inovações na produção noticiosa e os modos como jovens consomem notícias. Este trabalho aponta características de conteúdos e formatos audiovisuais direcionados ao público juvenil, mediante uma análise dos sites BuzzFeed Brasil, Vice Brasil, AJ+e NowThis News. Este estudo também identifica as maneiras como universitários do Rio de Janeiro se relacionam com as notícias, aferidas com a aplicação de questionários on-line com seis grupos de estudantes no Facebook. Assim, o artigo aponta tendências e desafios das práticas jornalísticas na atualidade.

Palavras-chave: Inovação. Juventude. Notícia. Conteúdos e formatos audiovisuais. Consumo.

\section{Abstract}

Reflecting on incoming journalism implies thinking on innovations in news production and on ways which young people consume news. This paper highlights trends in audiovisual news contents and formats aimed at young people, through an analysis of the sites BuzzFeed Brasil, Vice Brasil, AJ + and NowThis News. This study also identifies the ways in which undergraduates of Rio de Janeiro relate to the news measured by online questionnaires applied in six groups of students on Facebook. Thus, the article points out trends and challenges of current journalistic practices.

Keywords: Innovation. Youth. News. Audiovisual contents and formats. Consumer.

\section{Introdução}

As redes digitais e suas apropriações permeiam as interações cotidianas e promovem mudanças nas formas de socialização, nas relações afetivas e nos modos de compreender a realidade. A produção e o consumo de informações em redes afetam as formas de organização de instituições, empresas e comunidades. Neste contexto, o jornalismo também sofre transformações que desafiam o exercício da profissão e provocam questionamentos sobre a epistemologia desse campo de saber. $\mathrm{O}$ atual insucesso dos modelos de negócio das mídias tradicionais, as pressões de mercado e a sua demanda por inovação, o enxugamento dos investimentos publicitários, a precarização das condições de trabalho dos jornalistas, as expressivas demissões, as oportunidades profissionais abertas pelo empreendedorismo, a migração e a proliferação da produção e do consumo de notícias para plataformas digitais no ambiente midiático, as reconfigurações das relações entre jornalistas, fontes e leitores são fenômenos complexos que têm demandado estudos vigorosos dos pesquisadores em jornalismo. O desalinhamento entre ideais éticos da profissão e as narrativas da mídia tradicional no Brasil sobre política revelam hiatos entre os princípios da disciplina e as práticas jornalísticas. 
E a confiança e a credibilidade das notícias ficam ameaçadas. Assim, a autoridade dos jornalistas como narradores exclusivos das histórias do presente é questionada (BECKER, 2011). Entretanto, o jornalismo sempre enfrentou a contradição de atender ao interesse público com a oferta de notícias sob construções discursivas dos fatos, direcionadas pelas aspirações políticas e econômicas de grandes empresas, mais motivadas pela obtenção de lucros do que na prestação de um serviço de informação de qualidade sobre a vida social. Se a academia já superou a compreensão de notícia como espelho da realidade, sugerindo que esta é uma construção social da realidade, a relação do conceito de notícia com a produção da verdade ainda é complexa. Os relatos jornalísticos são impregnados de subjetividades, e a objetividade pode encobrir as relações de poder e as contradições dos fatos (SHUDSON, 2010). A notícia poderia ser definida, segundo Alsina (2009), como uma representação social da realidade cotidiana, produzida institucionalmente, que se manifesta na construção de um mundo possível, uma versão da realidade descrita. As representações sociais costumam ter uma continuidade histórica, por meio processos cognitivos e emotivos que geram significações, esquemas de organização de sentidos e realidades simbólicas. A construção das notícias está relacionada à cultura e à ideologia, mas sofre mudanças em acordo com um determinado contexto e a perspectiva dos observadores. Compreende-se que a responsabilidade do processo comunicativo proposto pelo jornalismo não é apenas das instâncias produtivas e dos jornalistas, mas também de leitores que nem sempre atuam de forma desinteressada (Ibid.).

Nesse sentido, refletir sobre jornalismo implica pensar também a atuação das audiências. Interessados em tecer perspectivas sobre o futuro do jornalismo, entre todos os complexos fenômenos anteriormente elencados, que caracterizam as reflexões no campo e no exercício da profissão na atualidade, consideramos que o estudo dos modos como o conceito de inovação se manifesta no jornalismo e de formas de produção e consumo de notícias em áudio e vídeo direcionada ao público juvenil nos oferecem pistas relevantes para alcançarmos nossos objetivos. Por um lado, o estudo de características de tratamento de informação e de linguagem de sites jornalísticos nacionais e internacionais dirigidos a jovens nos revela tendências das atuais práticas jornalísticas, especialmente de estratégias de interação com as redes sociais e de uso de códigos audiovisuais na construção dos relatos. Por outro, o entendimento das maneiras como jovens universitários expressam seus interesses pelas notícias na atualidade, atribuem valores a essa prática social, se apropriam e compartilham relatos noticiosos, nos permite refletir sobre a relevância potencial do jornalismo para novas gerações. Partimos da hipótese que muitos aspectos da disciplina e do exercício da profissão têm se transformado. Porém, as relações do 
jornalismo com as instituições sociais e as formas de produção e de organização dos relatos jornalísticos sobre os acontecimentos cotidianos não sofreram grandes mudanças. Os interesses comerciais prevalecem e as normas e as éticas profissionais se mantêm como premissas nem sempre concretizadas. Contudo, o jornalismo ainda exerce função social relevante no ambiente midiático convergente, caracterizado pela coexistência de antigos e novos modelos de produção de conteúdo noticioso.

\section{Jornalismo, inovação e juventude}

Phillips (2015) argumenta que a ideologia e o poder não deixaram de se manifestar nos modelos de jornalismo do século 21 e o determinismo tecnológico não garante o entendimento de suas atuais características. As tecnologias mudaram, mas a atividade jornalística de coletar, analisar e disseminar informações são ainda realizadas em diferentes plataformas (Ibid.). No entanto, a produção jornalística na internet é marcada tanto por práticas inovadoras quanto por iniciativas de negócios oportunistas e tem aberto possibilidades para grandes organizações de mídia dominarem os mercados nacionais e internacionais, direcionando as audiências para o consumo de seus produtos, o que resulta em uma homogeneização de conteúdos e formatos noticiosos. Küng (2015) destaca que a cultura pró-digital dissolve tradicionais concepções sobre o que é notícia sob a diretriz da inovação. Porém, os novos modelos de negócios no ambiente digital convergente ainda não estão sedimentados, e o entendimento do conceito de inovação apenas como uma oportunidade de negócios não incorpora tensionamentos que caracterizam a produção jornalística e o próprio estágio de desenvolvimento do capitalismo e das práticas socioculturais contemporâneas. A inovação constituiu-se como diretriz de diferentes atividades produtivas em um contexto de predominante manifestação de doutrinas neoliberais - Estado mínimo, desmantelamento das relações de trabalho e promoção de um ideário competitivo (CASTELLS, 2000; DELEUZE, 1992; EHRENBERG, 2010). Entendida como a exploração bem-sucedida de novas ideias, produtos, serviços, áreas de atuação ou processos, a inovação emergiu no campo econômico no contexto da Grande Depressão, a partir obra de Joseph Schumpeter (1997), para descrever novidades inseridas em um determinado sistema produtivo que o desestabiliza e provoca mudanças. A inovação pode emergir de um novo uso para uma tecnologia existente, criação de um novo modelo de negócios, ou a simples disponibilização do produto ou serviço num novo local ou para um público anteriormente mal atendido (RIES, 2012). Entretanto, segundo Christensen (2011), melhorias em produtos e serviços não são capazes de garantir o crescimento e a consolidação de organizações produtivas na 
atualidade, somente inovações radicais. Embora reconheça a importância da inovação para o desenvolvimento da sociedade, Piketty (2014) também relativiza seu alcance para superar as desigualdades sociais. O autor destaca que a inovação pode gerar rupturas em um o momento histórico específico, mas grandes empreendedores tendem a se transformar em rentistas. No entanto, a inovação reflete mudanças de valores, comportamentos e visões de mundo em diversos segmentos produtivos da sociedade, é uma resposta a transformações estruturais decorrentes tanto do cenário econômico quanto das práticas socioculturais na contemporaneidade e ganha repercussão no jornalismo em um momento em que este campo enfrenta desafios econômicos e políticos.

A inovação promove tanto modelos de negócios que priorizam a lucratividade em detrimento da qualidade da informação noticiosa, quanto experiências de produção, distribuição e consumo de notícias mais autônomas, dialógicas e polifônicas. Briggs (2012) reflete que empreendedores individuais e organizações midiáticas mais bem-sucedidos são as que propuseram um jornalismo mais colaborativo, envolvendo o público nos processos de construção da notícia e abraçando a diversidade de vozes. Longhi e Flores (2017) direcionam suas atenções a formatos noticiosos inovadores, como as longforms, narrativas jornalísticas mais bem elaboradas com uso recorrente de recursos multimídia e imersivos capazes de incrementar a qualidade do jornalismo. Esses autores concentram sua abordagem no jornalismo enquanto um setor produtivo para refletir a inovação nas estruturas organizacionais e nos relatos noticiosos. Mas Franciscato (2010) sublinha a importância de inovações de caráter social, que envolvem usos e efeitos sociais dos processos interativos, bem como as dinâmicas entre agentes sociais e as organizações jornalísticas. Essa abordagem nos permite compreender a inovação no jornalismo como dinâmicas e tensões oriundas de formas emergentes de produção e de consumo de notícias caracterizadas pela incorporação de tecnologias digitais em busca de uma aproximação maior com as audiências e de um modelo de negócios rentável. O público, cada vez mais disperso no ambiente digital e habituado ao consumo e compartilhamento de informações e notícias por meio das redes sociais (ZAGO, 2013), desafia as organizações jornalísticas tradicionais. A necessidade de atrair e fidelizar novos públicos e segmentos, especialmente os mais jovens, exige das empresas estratégias inovadoras, por meio de novas linguagens e formatos. Para identificar estratégias de portais noticiosos utilizadas para capturar a atenção e o interesse do público juvenil, realizamos um mapeamento de iniciativas no Brasil e no mundo, tanto de grandes empresas já consolidadas, quanto de startups jornalísticas emergentes da internet. ${ }^{1}$

1 As startups jornalísticas são empreendimentos vinculados tanto ao individualismo econômico, quanto à inovação, resistência e autonomia para produzir relatos jornalísticos mais plurais (BECKER \& WALTZ, 2017). 
Interessados em apontar tendências de consumo de conteúdos e formatos noticiosos audiovisuais direcionados a jovens e identificar as maneiras como eles atribuem valor e se relacionam com as notícias no ambiente midiático convergente, realizamos ainda uma pesquisa com estudantes de comunicação e de jornalismo no Rio de Janeiro, por meio da aplicação de questionários on-line.

Entretanto, este estudo da produção e consumo de notícias nos exige antes desvelar o conceito de juventude, aqui reconhecido como " uma experiência que contempla multiplicidades e que não corresponde a uma condição 'natural' do ser humano, pois é fundamentada em elementos que variam conforme a época e as condições políticas e socioculturais" (CATANI; GILIOLI, 2008, p. 104). Desde o século 19 tenta-se definir o que é o jovem. Biologicamente, é uma fase intermediaria entre a infância e a vida adulta, mas sem limites precisos. Não há um consenso universal sobre o conceito de juventude, um fenômeno de sociedades modernas e industrializadas. As definições possíveis que delimitam as noções de juventude envolvem a faixa etária; a determinação de maturidade/imaturidade por padrões biológicos ou psicológicos; parâmetros de normalidade que normatizam o que é desejável ou não de populações designadas como jovens, por meio dos discursos políticos, mercadológicos e acadêmicos; critérios socioeconômicos; fatores como gênero e etnicidade e estilos de vida. (CATANI; GILIOLI, 2008; FEIXA, 1998; FREIRE FILHO, 2008; SAVAGE, 2009). ${ }^{2}$ Mas como são múltiplas as manifestações dos jovens, é possível falar-se em diferentes juventudes e culturas juvenis. A faixa etária tende a ser utilizada como principal definidor dos limites da juventude nessas ações. Porém, é cada vez mais frequente a elaboração de categorias geracionais que incorporam, além da idade, aspectos culturais e comportamentais. A chamada geração internet, por exemplo, também nomeada de Geração do Milênio ou Geração Y, interage com múltiplas telas e mídias, compartilha conhecimentos na rede, intervém nas reconfigurações dos modelos de negócios e transforma o mercado de trabalho (TAPSCOTT, 2010). Entretanto, essa geração também interage com práticas socioculturais tradicionais de maneiras distintas, inclusive com o jornalismo. $\mathrm{O}$ hibridismo cultural, a internacionalização de valores e a diversidade de estilos de vida

2 A juventude ainda é definida, em cada país, de formas distintas no âmbito institucional. No Brasil, graças à mobilização de diversos movimentos sociais, é criado em 1990 o Estatuto da Criança e do Adolescente, lei que trata da proteção integral dos indivíduos menores de 12 e 18 anos. A Política Nacional de Juventude é implementada em 2005. O projeto da Secretaria Nacional da Juventude, vinculada à Secretaria Geral da Presidência da República, visa fomentar ações voltadas para o segmento juvenil. O Estatuto da Juventude, aprovado em 2013, estabelece como jovem todas "as pessoas com idade entre 15 (quinze) e 29 (vinte e nove) anos de idade". E o Censo 2010 estimou que o Brasil possui mais de 50 milhões de indivíduos nesta faixa etária, cerca de $25 \%$ da população brasileira. Disponível em: <https://bit.ly/2xm9kIn>; <https://bit.ly/1MzlCIG>; <https://bit.ly/2xlxbI9>; <https://bit.ly/2JxFUt1>; <https://bit.ly/2sfYcb7>. Acesso em: 18 set. 2017. 
têm influenciado sobremaneira a construção das identidades juvenis. Os gostos e escolhas dos jovens tendem a gerar visões de mundo, da política e do trabalho diferentes e são fortemente marcados pela midiatização e pela interconectividade na chamada pós-modernidade. $\mathrm{O}$ acirramento das políticas neoliberais e a decadência de instituições tradicionais estimulam a satisfação de desejos em um presente imediato e fazem proliferar produtos e consumos centrados no sujeito e em seu bem-estar. O desencanto pelos modelos clássicos de representação política se associa à visão de um mundo baseado na centralização do self, menos preocupado com o outro e a sociedade. No entanto, as novas redes de sociabilidade também se configuram em processos dinâmicos de reivindicação de direitos e geram novas formas de ações coletivas, como o ativismo social (MACHADO, 2011). Assim, a juventude deixa de ser exclusivamente observada como um grupo vinculado ao entretenimento e ao consumo e avesso à política na atualidade. $\mathrm{O}$ avanço das tecnologias da informação e comunicação permite aos jovens estabelecerem diferentes redes que não se organizam mais apenas pela geografia, mas sim pelos interesses e afetos particulares dos indivíduos (MOCARZEL, 2017). Os "nativos digitais" articulam diferentes linguagens, elaboram memes, criam músicas, produzem conteúdos e desenvolvem formas de atuações políticas nas redes.

$\mathrm{Na}$ área da comunicação, uma das maiores preocupações dos pesquisadores é entender como os jovens se relacionam com os meios de comunicação. Porém, as formas de consumo de notícias não se constituem como objeto recorrente nessas pesquisas, como foi possível verificar em um estudo dos trabalhos apresentados nos últimos cinco anos nos Grupos de Trabalho (GT) Estudos de Jornalismo e Recepção: processos de interpretação, usos e consumo midiáticos da Associação Nacional dos Programas de Pós-Graduação em Comunicação (COMPÓS). ${ }^{3}$ Neste trabalho, buscamos compreender os modos como os jovens universitários do estado do Rio de Janeiro se relacionam com as práticas jornalísticas na atualidade, observando como se estabelece a relação entre juventude e notícias, o que nos oferece pistas relevantes para pensarmos o futuro do jornalismo. Para isso, realizamos uma análise de portais que disponibilizam conteúdos noticiosos audiovisuais direcionados ao público juvenil e, em seguida, apresentamos os modos que esses jovens universitários consomem notícias e atribuem valor ao jornalismo.

3 Disponível em: <https://bit.ly/2ISunDP>. Acesso em: 9 nov. 2017. No GT Estudos de Jornalismo, entre 50 trabalhos, apenas sete abrem espaço para compreender melhor as práticas de leitura das notícias, sua circulação e produção de sentidos. A leitura do resumo dos 49 artigos disponíveis no banco de dados do GT de Recepção permitiu identificar que a maioria das investigações enfoca a televisão e suas relações com as audiências, somente três trabalhos se debruçam sobre o jornalismo e um deles apresenta dados sobre o consumo midiático de jovens da região Sul do país (JACKS et al, 2014). 


\section{Tendências da produção noticiosa direcionada ao público juvenil}

Tomamos como critérios de formação do corpus deste nosso estudo, empreendimentos jornalísticos direcionados de maneira explícita em suas normas editoriais a um público jovem, de 18 a 34 anos de idade; que empregam conteúdos audiovisuais e multimídia, e interagem com outras plataformas e redes sociais. Selecionamos quatro portais ${ }^{4}$ : Buzzfeed Brasil, Vice, NowThis News e AJ+, representados na Figura 1. Os dois primeiros têm filiais no Brasil e produção para o público nacional. $\mathrm{O} \mathrm{AJ}+$, uma iniciativa do grupo $\mathrm{Al}$ Jazeera, baseado no Qatar, e a startup NowThis News são sediados nos Estados Unidos.

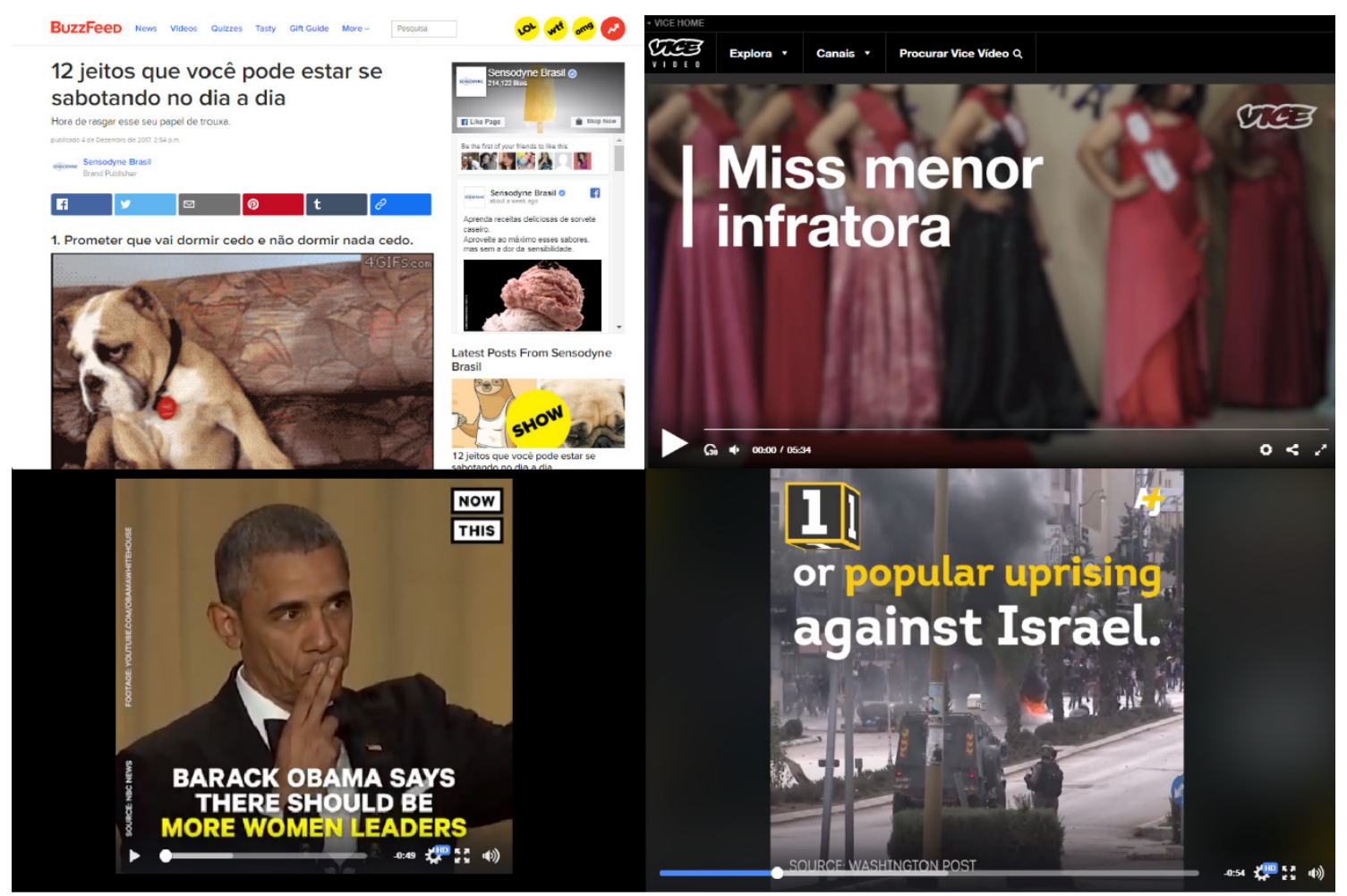

Figura 1. Publicações veiculadas pelo Buzzfeed Brazil, Vice Brasil, AJ+e NowThis (sentido horário), entre os dias $1^{\circ}$ e 11 de dezembro de 2017

Fonte: Elaboração dos autores.

Esses veículos digitais eram direcionados à produção de documentários e de conteúdos de entretenimento. Porém, decidiram investir na produção de notícias e adotaram estratégias para atrair audiências juvenis, anunciantes e investidores. O BuzzFeed Brasil, o Vice Brasil, o AJ+ e o NowThis News representam tendências da produção noticiosa direcionada

4 Endereços dos portais: < https://www.buzzfeed.com/?country=br $>$; $<$ https://www.vice.com/pt_br $>$; $<$ https:// nowthisnews.com/>; <www.ajplus.net/>.

$96 \frac{\text { Comunicação \& Inovação, PPGCOM/USCS }}{\text { v. 19, n. } 40 \text { (89-105) maio-ago } 2018}$ 
ao público juvenil em diferentes continentes e são aqui identificados como "inovadores digitais”, por reunirem características que, em acordo com Küng (2015), refletem estratégias adotadas por diferentes portais jornalísticos que implantaram modelos de negócio de sucesso. Para apontar tendências da produção de conteúdos e formatos noticiosos audiovisuais direcionados aos jovens, realizamos uma análise comparativa da produção desses sites durante dez dias, de $1^{\circ}$ a 11 de dezembro de 2017, por meio da aplicação de cinco categorias analíticas inspiradas na pesquisa de Küng (Ibid.): (i) Objetivos e estratégia comercial; (ii) Características das homepages; (iii) Usos e formatos de vídeos (iv) Interações com as redes sociais; e (v) Linguagens e temáticas do conteúdo. Realizamos uma leitura crítica dos conteúdos noticiosos desses quatro portais publicados no Facebook, uma vez que todos privilegiam suas interações com esta plataforma e o NowThis não possui um repositório de matérias ou homepage fora das redes sociais. Assim, foi possível sistematizar as suas principais características inovativas de produção noticiosa, demonstradas no quadro a seguir:

Quadrro 1. Comparativo da produção audiovisual noticiosa

\begin{tabular}{|c|c|c|c|c|}
\hline Portais & BuzzFeed Brasil & Vice Brasil & $\mathrm{AJ}+$ & NowThis News \\
\hline $\begin{array}{l}\text { Objetivos e } \\
\text { estratégia } \\
\text { comercial }\end{array}$ & $\begin{array}{l}\text { Criado nos Estados } \\
\text { Unidos em } 2006 \\
\text { pelo jornalista Jonah } \\
\text { Peretti. Investimentos } \\
\text { da NBC Universal } \\
\text { e Viacom. Fonte de } \\
\text { receita: publicidade e } \\
\text { produção de conteúdo } \\
\text { pago. Campanhas } \\
\text { com conteúdo e } \\
\text { formato idênticos } \\
\text { às matérias não } \\
\text { patrocinadas. }\end{array}$ & $\begin{array}{l}\text { Surgiu nos anos } \\
1990 \text { no Canadá, } \\
\text { fundado por Shane } \\
\text { Smith. Recebeu } \\
\text { investimentos de } \\
\text { conglomerados } \\
\text { de mídia e de } \\
\text { investidores } \\
\text { privados. Vende } \\
\text { espaço de anúncios } \\
\text { no site e elabora } \\
\text { conteúdos } \\
\text { informativos com } \\
\text { grandes marcas para } \\
\text { o público juvenil. }\end{array}$ & $\begin{array}{l}\text { Criado pela Al } \\
\text { Jazeera em } 2014 . \\
\text { Atua em } 130 \text { países. } \\
\text { Busca consolidar } \\
\text { a presença da } \\
\text { emissora no mercado } \\
\text { norte-americano, } \\
\text { a ampliação da } \\
\text { audiência e formas } \\
\text { inovadoras de } \\
\text { expansão da cobertura } \\
\text { jornalística. } 40 \% \text { de } \\
\text { sua audiência nos EUA } \\
\text { tem entre } 18 \text { e } 34 \text { anos. } \\
\text { Ainda não monetiza } \\
\text { seu conteúdo. }\end{array}$ & $\begin{array}{l}\text { Startup fundada em } \\
2012 \text { pelo jornalista } \\
\text { Kenneth Lerer. } \\
\text { Integra a holding } \\
\text { Group Nine Media. } \\
\text { Recebe investimentos } \\
\text { do grupo Discovery } \\
\text { Communications. } 75 \% \\
\text { do seu público tem } \\
\text { menos de } 35 \text { anos. } \\
\text { Produz exclusivamente } \\
\text { conteúdo audiovisual. } \\
\text { Modelo de negócios } \\
\text { baseado na produção de } \\
\text { conteúdo pago. }\end{array}$ \\
\hline $\begin{array}{l}\text { Homepages, } \\
\text { armazenamento } \\
\text { e acesso }\end{array}$ & $\begin{array}{l}\text { Interface assemelha- } \\
\text { se à de um portal de } \\
\text { notícias "tradicional", } \\
\text { Conteúdos novos } \\
\text { e republicações } \\
\text { programados } \\
\text { para serem } \\
\text { disponibilizados } \\
\text { durante todo o dia. } \\
\text { Postagens específicas } \\
\text { para a redes sociais. }\end{array}$ & $\begin{array}{l}\text { A home brasileira } \\
\text { recebe atualizações } \\
\text { quase diárias. } \\
\text { O conteúdo é } \\
\text { armazenado no Vice } \\
\text { Video e é alimentado } \\
\text { por profissionais de } \\
34 \text { países. Parte é } \\
\text { distribuída em redes } \\
\text { sociais }\end{array}$ & $\begin{array}{l}\text { Não possui } \\
\text { homepage com } \\
\text { atualização diária. Na } \\
\text { página, há links para } \\
\text { os vídeos produzidos } \\
\text { pela empresa, } \\
\text { armazenados } \\
\text { no YouTube e } \\
\text { compartilhados em } \\
\text { outras redes, como } \\
\text { Twitter e Facebook. }\end{array}$ & $\begin{array}{l}\text { Não possui homepage. O } \\
\text { portal apenas apresenta } \\
\text { a sua política editorial } \\
\text { e contatos publicitários. } \\
\text { O conteúdo é veiculado } \\
\text { e armazenado por } \\
\text { meio das redes sociais } \\
\text { e aplicativos para } \\
\text { dispositivos móveis. }\end{array}$ \\
\hline
\end{tabular}


Quadro 1. Continuação

\begin{tabular}{|c|c|c|c|c|}
\hline Portais & BuzzFeed Brasil & Vice Brasil & $\mathrm{AJ}+$ & NowThis News \\
\hline $\begin{array}{l}\text { Usos e formatos } \\
\text { de vídeos }\end{array}$ & $\begin{array}{l}\text { Hibridismo de } \\
\text { linguagens. Os } \\
\text { vídeos são um dos } \\
\text { recursos textuais do } \\
\text { portal explorados } \\
\text { com a mesma ênfase } \\
\text { que textos verbais } \\
\text { combinados com } \\
\text { imagens fixas, gifs e } \\
\text { memes e de "lista", } \\
\text { formato que se tornou } \\
\text { uma das marcas do } \\
\text { site, utilizado para } \\
\text { sintetizar ou explicar } \\
\text { com brevidade uma } \\
\text { notícia. }\end{array}$ & $\begin{array}{l}\text { Produziu um } \\
\text { programa de } 30 \\
\text { minutos para a } \\
\text { HBO, o Vice News, } \\
\text { e lançou em } 2016 \\
\text { o Viceland, canal } \\
\text { pago de TV com } \\
\text { o A\&E Networks } \\
\text { em diferentes } \\
\text { países. No Brasil, } \\
\text { tem parceria com } \\
\text { a programadora de } \\
\text { TV a cabo Globosat. } \\
\text { As imagens são } \\
\text { trabalhadas de } \\
\text { maneira inventiva. }\end{array}$ & $\begin{array}{l}\text { Vídeos curtos, } \\
\text { explicativos e } \\
\text { "compartilháveis", } \\
\text { chamados "dabs". } \\
\text { Uso de música } \\
\text { instrumental, de } \\
\text { legendas e intertítulos } \\
\text { na edição desses } \\
\text { conteúdos. Não } \\
\text { há narração em } \\
\text { off. Informações } \\
\text { ressaltadas, por meio } \\
\text { da inserção de texto } \\
\text { verbal nas imagens. } \\
\text { Os vídeos são } \\
\text { produzidos em três } \\
\text { diferentes idiomas. }\end{array}$ & $\begin{array}{l}\text { Vídeos curtos e } \\
\text { "compartilháveis". } \\
\text { Uso de trilha sonora } \\
\text { e legendas em inglês. } \\
\text { Não há narração em } \\
\text { off. Palavras e frases } \\
\text { inseridas nos vídeos } \\
\text { destacam as informações } \\
\text { consideradas mais } \\
\text { importantes pelos } \\
\text { editores. }\end{array}$ \\
\hline $\begin{array}{l}\text { Interações com } \\
\text { as redes }\end{array}$ & $\begin{array}{l}\text { O portal privilegia } \\
\text { o próprio website. A } \\
\text { página do portal no } \\
\text { Facebook registrava } \\
2,3 \text { milhões } \\
\text { de curtidas até } \\
\text { dezembro de } 2017 \text {. } \\
\text { Oferece recursos de } \\
\text { interatividade. Os } \\
\text { usuários cadastrados } \\
\text { no site podem avaliar } \\
\text { as postagens. }\end{array}$ & $\begin{array}{l}\text { O Facebook serve, } \\
\text { para alavancar o } \\
\text { acesso ao portal } \\
\text { com a média de } \\
25 \text { publicações } \\
\text { diárias. Mas } 40 \% \text { do } \\
\text { conteúdo é replicado. } \\
\text { Há pouca interação } \\
\text { com o público, } \\
\text { formado por } 408 \text { mil } \\
\text { seguidores. }\end{array}$ & $\begin{array}{l}\text { A página do AJ+ } \\
\text { no Facebook tem } \\
\text { mais de } 10 \text { milhões } \\
\text { de curtidas. O } \\
\text { portal investe em } \\
\text { transmissões ao vivo. } \\
\text { Conteúdo do YouTube } \\
\text { compartilhado } \\
\text { em redes sociais. } \\
\text { Enquetes e perguntas } \\
\text { buscam aproximação } \\
\text { com o público. }\end{array}$ & $\begin{array}{l}\text { Até } 2017 \text { foram } \\
\text { registrados } 13 \text { milhões } \\
\text { de fãs no Facebook, } \\
\text { onde são publicados } 40 \\
\text { vídeos em média por } \\
\text { dia. As redes sociais são } \\
\text { usadas para veiculação } \\
\text { e armazenamento de } \\
\text { conteúdo. Mas não } \\
\text { investe em interatividade } \\
\text { com as audiências. }\end{array}$ \\
\hline $\begin{array}{l}\text { Linguagens e } \\
\text { temáticas }\end{array}$ & $\begin{array}{l}\text { Produção de "notícias } \\
\text { light", dirigidas } \\
\text { ao entretenimento } \\
\text { e ao consumo } \\
\text { rápido via redes } \\
\text { sociais. Conteúdo } \\
\text { formado por um } \\
\text { "pacote" de notícias } \\
\text { factuais, matérias } \\
\text { investigativas, } \\
\text { testes, questionários, } \\
\text { listas e vídeos } \\
\text { sobre identidade, } \\
\text { experiências, receitas, } \\
\text { cultura e vida } \\
\text { cotidiana. A política } \\
\text { editorial ressalta que o } \\
\text { conteúdo é destinado } \\
\text { à nova geração e ao } \\
\text { compartilhamento em } \\
\text { redes sociais. }\end{array}$ & $\begin{array}{l}\text { Conteúdos } \\
\text { patrocinados por } \\
\text { grandes empresas. } \\
\text { Matérias sobre } \\
\text { cultura, música e } \\
\text { tecnologias também } \\
\text { são publicadas e } \\
\text { tendem a valorizar } \\
\text { o aspecto humano } \\
\text { das histórias. Mas } \\
\text { o principal foco é o } \\
\text { entretenimento. O } \\
\text { "Boletim Matutino } \\
\text { do Vice" do Vice } \\
\text { Brasil reflete o } \\
\text { interesse do portal } \\
\text { em notícias factuais, } \\
\text { lincadas à Folha de } \\
\text { S. Paulo e ao G1. }\end{array}$ & $\begin{array}{l}\text { A produção de } \\
\text { notícias não é } \\
\text { diária. As principais } \\
\text { temáticas do } \\
\text { conteúdo noticioso } \\
\text { audiovisual } \\
\text { são: Política, } \\
\text { especialmente } \\
\text { questões de interesse } \\
\text { norte-americano e } \\
\text { do Oriente Médio, } \\
\text { causas humanitárias } \\
\text { e histórias que } \\
\text { ressaltam valores } \\
\text { humanistas. }\end{array}$ & $\begin{array}{l}\text { O conteúdo é formado } \\
\text { por breaking news e } \\
\text { entretenimento. No } \\
\text { Facebook apresenta } \\
\text { páginas com temáticas } \\
\text { específicas, semelhante } \\
\text { a editorias, como } \\
\text { o NowThis Future } \\
\text { (tecnologia, ciência e } \\
\text { inovação); NowThis } \\
\text { Her (empoderamento } \\
\text { feminino e desigualdade } \\
\text { de gênero); NowThis } \\
\text { Politics (cobertura } \\
\text { política) e NowThis } \\
\text { Weed (descriminalização } \\
\text { e legalização da } \\
\text { maconha). Engajamento } \\
\text { político progressista. }\end{array}$ \\
\hline
\end{tabular}

Fonte: Elaboração dos autores. 
Os conteúdos e formatos audiovisuais noticiosos são formas de conhecimentos que exercem papel relevante no ecossistema midiático na construção e na percepção de nossa realidade social cotidiana, e contam a história do presente por meios de uma tessitura singular de imagens e palavras. Mas não são uma representação exata do mundo real e suas combinações de códigos áudio-verbo-visuais, também exigem ações interpretativas por parte das audiências, as quais atribuem significações aos acontecimentos. Assim, entendemos que refletir sobre o futuro do jornalismo nos exige investigar também como a juventude interage com esses textos jornalísticos.

\section{Consumo de notícias por jovens universitários}

Para verificar experiências juvenis de consumo de notícias, selecionamos seis grupos on-line formados por estudantes de comunicação e de jornalismo de seis universidades públicas e privadas sediadas no estado do Rio de Janeiro - Universidade Federal do Rio de Janeiro (UFRJ); Universidade Estadual do Rio de Janeiro (UERJ); Universidade Federal Fluminense (UFF); Universidade Federal Rural do Rio de Janeiro (UFRRJ); Pontifícia Universidade Católica do Rio de Janeiro (PUC-Rio) e Universidade Veiga de Almeida (UVA). Construímos um questionário com seis perguntas objetivas e oito discursivas, e fizemos um convite a esses jovens para respondê-lo em seus grupos no Facebook, os quais reúnem, em média, 2.200 membros. ${ }^{5}$ Verificamos que 80 por cento dos respondentes tinham idades entre 18 e 24 anos; 14 por cento representava a faixa etária entre 25 a 29 anos e cinco por cento tinham de 30 a 34 anos de idade. Assim, compreendemos que esses grupos juvenis convergem interesses de estudantes, não delimitados, exclusivamente, pela faixa etária, como antes refletimos sobre o conceito de juventude. O mesmo questionário foi aplicado durante dez dias em quatro períodos distintos: entre 22 de maio e 2 de junho, 11 e 22 de julho, 15 e 26 de setembro e 31 de outubro e 11 de novembro de 2017. Obtivemos 57 respostas: 44 de alunos da UFRJ, 28 da UERJ, 14 da UVA, 11 da PUC-Rio, dois da UFF e dois também da UFRRJ. Consideramos esta mostra significativa, uma vez que as perguntas exigiam não apenas a identificação dos respondentes, mas também a disponibilidade para a realização de entrevistas semiestruturadas e a dedicação de um tempo estimado de mais de quinze minutos para elaboração e expressão das respostas escritas. O principal objetivo do questionário era compreender os seus modos de consumir e partilhar notícias, os valores atribuídos às práticas jornalísticas e aos jornalistas e a percepção desses jovens sobre a relação entre inovação e o futuro do jornalismo.

5 Disponível em: $<$ https://bit.ly/2L01sOS $>$; $<$ https://bit.ly/2iloiqZ $>$; $<$ https://bit.ly/2IRNn9H $>$; $<$ https://bit.ly/ 2GY4bWz>; <https://bit.ly/2J8wB5v>; <https://bit.ly/2sg5VG9>. Acesso em: 28 maio 2018. 
Identificamos neste estudo que o acesso à informação jornalística de $100 \%$ dos universitários que participaram da pesquisa é por meio da internet. A televisão aberta ou paga é a segunda opção para $78,9 \%$ dos respondentes se atualizarem sobre os principais acontecimentos do Brasil e do mundo. Os jornais impressos correspondem à escolha de $47,4 \%$ e as emissoras de rádio a $19,3 \%$ dos jovens. Os portais jornalísticos de grandes organizações de mídia foram considerados as principais fontes de notícias para 91,2\% dos respondentes, seguidos pelo Facebook, acessado por $86 \%$ dos participantes com este objetivo. Os estudantes afirmaram usar também diferentes tipos de plataformas para acessar informações, como os portais direcionados ao público juvenil analisados. As editorias de maior interesse são as de cultura e de entretenimento, seguidas da editoria de política. As principais motivações para acessar uma notícia incluem o interesse prévio e pessoal no assunto tratado; o título, as imagens e os recursos de mídia empregados no texto; a curiosidade por acontecimentos extraordinários; o interesse em apreender informações não disponíveis nas redes sociais; a necessidade de constante atualização; a credibilidade do veículo e a vontade de avaliar distintas formas de abordagem dos fatos em diferentes plataformas. Apesar da maioria dos estudantes acessar notícias todos os dias, apenas 50,9\% dos universitários as compartilham. Aqueles que adotam este hábito preferem utilizar o Twitter para endossar o ponto de vista de uma determinada matéria. Eles apontam que o conteúdo compartilhado deve ser constituído por "Informações úteis sobre política, educação ou mesmo do entretenimento", "reportagens diferentes e inovadoras" ou "coisas curiosas", mas também compartilham informações que consideram importantes para as suas redes de amigos e/ou tenham impacto na vida das pessoas. Quase todos os respondentes afirmam que não é possível identificar quantas pessoas acessaram a informação. E a maioria destaca que conteúdo em vídeo é importante para atrair a atenção dos jovens. Os respondentes manifestam interesse por reportagens multimídias, vídeos no YouTube e no Facebook, inclusive ao vivo, e grande parte deles afirma que conteúdo televisivo é mais confiável, uma vez que "a credibilidade da internet é bastante volátil, porque tudo pode ser tido como verdade", como disse um estudante de jornalismo da UFRJ. Porém, grande parte dos universitários procura verificar por conta própria a credibilidade de conteúdos noticiosos e de maneiras diversas: averiguam o nome e a reputação do veículo, as mídias que noticiaram o fato, comparam dados, verificam as fontes, ouvem professores e colegas que trabalham em meios de comunicação, acompanham o histórico do assunto e os movimentos sociais e observam até mesmo a ortografia. A pesquisa indica que os respondentes tendem a conferir maior credibilidade aos veículos de comunicação com linhas editoriais alinhadas com suas convicções ideológicas, mas percebem que "muitas das vezes essas mídias usam dos mesmos artifícios da grande mídia”, como acusações sem provas. 
Contudo, a maioria não deixa de creditar confiabilidade ao trabalho dos jornalistas. Os jovens que participaram da pesquisa consideram que o jornalista é um "tradutor da complexidade dos acontecimentos"; "é aquele que registra e faz a leitura dos fatos em sua época"; "tem como papel apurar e checar a veracidade das informações" e as tornam "mais completas e confiáveis", como destacaram jovens universitários da UERJ e da UFRJ. 55 dos 57 jovens afirmam que o jornalista é e ainda será necessário nas filtragens das notícias, pois "embora todos possam produzir e compartilhar conteúdos, o jornalista sempre terá credibilidade na checagem dos fatos e na apuração das notícias" e para "qualificar, organizar e filtrar o que chega ao público de forma ética e comprometida com a população", declararam um aluno da UERJ e outro da UFRJ. Os respondentes ressaltaram ainda a relevância do jornalismo na contemporaneidade, diante do incremento de notícias falsas nas redes: "A importância do jornalista está muito pautada, na atualidade, na separação do que é notícia verdadeira do que é boato", afirmou um estudante da UFF. "diria até que ele é uma forma de fazer resistência, sempre denunciando e mostrando a verdade sobre os fatos", disse o universitário da UVA. Entretanto, os jovens que participaram da pesquisa reconhecem que o cumprimento da função social do jornalismo exige a construção de notícias menos tendenciosas, como ressaltou este aluno da UERJ: "Se o jornalismo não se tornar menos parcial e mais pragmático ele perderá o respeito do cidadão comum, que já tende a desconfiar de jornais por considerarem muito ideológicos" e este outro aluno da UFRJ: "é perceptível a posição ideológica de muitos jornais ou/e aglomerados midiáticos, mas ainda é importante na formação de uma opinião crítica e para mediar debates acerca dos acontecidos". Em acordo com as respostas do questionário aplicado, o valor social do jornalismo para as futuras gerações dependerá da curadoria e da interpretação das informações, uma vez que a filtragem e a análise das notícias é essencial para a relevância desta prática social na sociedade contemporânea, como revelam as declarações de duas jovens universitárias da UFRJ e da PUC-Rio: "Suponho que a crônica, as colunas, os editoriais, o 'factchecking', o jornalismo cada vez menos 'neutro' venha tomar corpo e fazer a diferença no futuro" e "não importa a quantidade e a qualidade de informações que a internet consegue agrupar ou até filtrar por meio de algoritmos, um filtro humano que possa ressignificar essas informações para o público sempre será importante para desenvolver a compreensão dos fatos e o pensamento crítico do leitor/espectador/ouvinte".

Quando questionados sobre a relação entre inovação e jornalismo, os respondentes destacam que a incorporação de tecnologias digitais na produção e distribuição das notícias e o interesse dos meios em acompanhar as demandas do público são aspectos que conferem inventividade às práticas jornalísticas. Contudo, ressaltam que a inovação sempre foi necessária, uma vez que "o jornalismo obrigatoriamente se 
reinventa de tempos em tempos para atender às demandas da sociedade" e que "existe inovação no jornalismo quando há quebra dos grandes oligopólios de comunicação" e os jornalistas conseguem resgatar a credibilidade de seus relatos. Os universitários enfatizaram ainda que as formas de produção e circulação de notícias são cada vez mais aceleradas e o público precisa ter confiança nas notícias transmitidas, até porque tem maior capacidade de refutar o que lê e discutir os assuntos na atualidade. No entanto, eles sugerem que as empresas precisam investir em notícias mais atrativas, em novos formatos audiovisuais e em conteúdos capazes de despertar debates de temas importantes para a sociedade, produzindo reflexão crítica. Inovação no jornalismo também significa maior interação dos portais que disponibilizam conteúdos noticiosos com as pessoas, como ressalta uma jovem estudante da PUC-Rio: "Uma perspectiva de inclusão e participação do leitor no discurso do jornal, no contexto das redes sociais, por exemplo, ganha muita importância, além do desenvolvimento de apps especializados para disponibilizar notícias com mais praticidade".

\section{Considerações Finais}

A partir da observação dos quatro veículos jornalísticos digitais direcionados ao público juvenil, observa-se a hibridização de linguagens e suportes na elaboração das notícias, inventividade estética na experimentação de novos formatos em áudio e vídeo e de uso de textos verbais que se aproximam da linguagem coloquial, o que atende à demanda de jovens que participaram desta pesquisa. Contudo, verifica-se também estratégias de incremento de consumo de conteúdos noticiosos, por meio de redes sociais e dispositivos móveis, que atraem parcerias e aportes financeiros de grandes corporações que exercem expressivo poder político e econômico e controlam os "protocolos da rede" (FUCHS, 2014). Essas estratégias não geram, necessariamente, maior participação das audiências na produção de conteúdos noticiosos, o que seria uma ação inovativa, como pontuado pelos jovens universitários que responderam ao questionário aplicado. As atuais plataformas na rede permitem a socialização, mas normatizam as formas de interação e os jovens participam mais da distribuição de conteúdos, por meio de suas curtidas e compartilhamentos, do que como colaboradores na produção noticiosa.

Identificamos que nos portais estudados os conteúdos audiovisuais são centrados tanto em breaking news lincadas a notícias de mídias tradicionais, quanto em entretenimento, como as listas e testes do BuzzFeed. A notícia é utilizada como um dos recursos para atrair a fidelizar as audiências, mas não é o principal conteúdo dos portais direcionados ao público juvenil, e não deixa de ser suportada por interesses políticos e 
comerciais no ambiente digital. A tênue separação entre o que é anúncio publicitário e informação jornalística se torna cada vez menos nítida, em desencontro com os princípios do jornalismo e com a busca da verdade dos fatos na construção dos relatos noticiosos. O valor do jornalismo e dos jornalistas é reconhecido pelo grupo de jovens que responderam ao questionário como uma prática social capaz de contribuir para a democracia. Mas os universitários apontam que a importância da função social do jornalismo e dos jornalistas nas próximas décadas estará condicionada à oferta de informação com as devidas apuração e credibilidade e à promoção da diversidade. Entretanto, foi possível verificar ainda que conteúdos dos sites estudados são direcionados para as notícias de empresas de mídias tradicionais, o que não implica maior diversidade da cobertura de acontecimentos relevantes na vida social, mesmo que o uso de linguagem mais coloquial procure expressar maior cumplicidade com a juventude. A incessante busca de interações cada vez mais intimistas com as audiências tende a gerar uma fusão indissolúvel entre entretenimento e informação e entre o interesse de produtores e instituições políticas e financeiras que os sustentam.

Além disso, no atual cenário de convergência midiática, nossa análise da produção e consumo de notícias permitiu observar que a relevância das práticas jornalísticas e de conteúdos noticiosos direcionados à juventude não está exclusivamente relacionada à compreensão da inovação como estratégias de envolvimento das audiências, de incremento do uso de códigos audiovisuais, de renovação de formatos e linguagens e ao seu espalhamento em múltiplas plataformas, mas, especialmente às maneiras como os jornalistas e as audiências estabelecem relações de confiabilidade. A inovação do jornalismo porvir implica na efetiva abertura para o outro e depende, fundamentalmente, da valorização do trabalho humano e do jornalista na produção de um jornalismo de maior qualidade, como ressaltado pelos respondentes. O empreendedorismo abre espaço para enunciações de atores sociais diversos sobre acontecimentos da realidade e contribui para a geração de construções de identidade e valores sociais, mas muitas vezes busca na parceria com a mídia tradicional a permanência e a sobrevivência das atividades jornalísticas pretendidas. Assim, o uso da narrativa jornalística para interesses políticos dos produtores de informação tanto nas mídias tradicionais quanto emergentes não tende a promover o engajamento dos universitários. Neste contexto, este estudo aponta que o jornalismo porvir pode reafirmar a importância de seu papel social para futuras gerações como prática social capaz de contribuir para a democracia, mas somente mediante a reafirmação da singularidade de sua mediação: a apuração e a checagem da veracidade dos fatos, a contextualização dos acontecimentos e a inclusão da pluralidade de vozes na construção das notícias e de um mundo possível. 


\section{Referências}

ALSINA, M. R. A construção da notícia. Petrópolis: Vozes, 2009.

BECKER, B. Desafios da profissão, do ensino e da pesquisa em jornalismo. In: KISCHINHEVSKY, M.; IORIO, F. M.; VIEIRA, J. P. D. Horizontes do jornalismo. Rio de Janeiro: E-papers, 2011.

BECKER, B.; WALTZ, I. Mapping journalistic startups in Brazil: an exploratory study. In: ROBINSON, L.; SCHULZ, J.; WILLIAMS, A. (Orgs.). Brazil: media from the country of the future (Studies in media and communications). Bingley: Emerald, 2017. p. 113-135. (Volume 13). Disponível em: $<$ https://bit.ly/2x153F9>. Acesso em: 2 out. 2017.

BRIGGS, M. Entrepreneurial journalism: how to build what's next for news. Thousand Oaks: Sage, 2012.

CASTELLS, M. A sociedade em rede. 2. ed. São Paulo: Paz\&Terra, 2000.

CATANI, A. M.; GILIOLI, R. S. P. Culturas juvenis: múltiplos olhares. São Paulo: UNESP, 2008.

CHRISTENSEN, C. The innovator's dilemma: the revolutionary book that will change the way you do business. New York, HarperBusiness, 2011.

DELEUZE, G. Post-Scriptum sobre as sociedades de controle. In: Conversações. São Paulo: Editora 34, 1992. p. 219-226.

EHRENBERG, A. O culto da performance: da aventura empreendedora à depressão nervosa. Aparecida: Ideias e Letras, 2010.

FEIXA, C. De jóvenes, bandas y tribus: antropología de la juventud. Barcelona: Ariel, 1998. Disponível em: < https://bit.ly/2Jf0VLF>. Acesso em: 21 set. 2017.

FRANCISCATO, C. E. Uma proposta de incorporação dos estudos sobre inovação nas pesquisas em jornalismo. Estudos em Jornalismo e Mídia, Florianópolis, v. 7, n. 1, jan./jun. 2010. Disponível em: $<$ https://bit.ly/2sfexMq>. Acesso em: 11 ago. 2017.

FREIRE FILHO, J. Retratos midiáticos da nova geração e a regulação do prazer juvenil. In: BORELLI, H. S. S; FREIRE FILHO, J. (Orgs.). Culturas juvenis no século XXI. São Paulo: EDUC, 2008.

FUCHS, C. Social media, a critical introduction. Thousand Oaks: Sage, 2014.

JACKS, N. et al. Jovem e consumo midiático: dados preliminares do estudo piloto e da pesquisa exploratória. In: ENCONTRO ANUAL DA COMPÓS, 23., 2014, Belém. Anais..., Belém, COMPÓS, 2014. Disponível em: <https://bit.ly/2KYos0H>. Acesso em: 21 out. 2017.

KÜNG, L. Innovators in digital news. Oxford: University of Oxford, 2015.

LONGHI, R. R.; FLORES, A. M. M. Narrativas webjornalísticas como elemento de inovação: casos de Al Jazeera, Folha de S.Paulo, The Guardian, The New York Times e The Washington Post. Revista Brasileira de Ciências de Comunicação, São Paulo, v. 40, n. 1, p. 21-40, jan./abr. 2017. Disponível em: <https://bit.ly/2GWoPXe>. Acesso em: $1^{\circ}$ jun. 2017.

MACHADO, M. Consumo e politização: discursos publicitários e novos engajamentos juvenis. Rio de Janeiro: Mauad, 2011.

$104 \frac{\text { Comunicação \& Inovação, PPGCOM/USCS }}{\text { v. 19, n. } 40 \text { (89-105) maio-ago } 2018}$ 
Inovação e juventude: um estudo sobre produção e consumo de notícias e o Jornalismo porvir

MOCARZEL, M. S. M. V. Tempos e espaços das juventudes: conceitos e trajetórias. In: Culturas, consumo e representações midiáticas da juventude. PEREIRA, C. (Org.). Curitiba: Appris, 2017.

PHILLIPS, A. Journalism in context. Practice and theory for the digital age. Londres: Routledge, 2015.

PIKETTY, T. O capital no século XXI. Rio de Janeiro: Intrínseca, 2014.

RIES, E. A startup enxuta: como os empreendedores atuais utilizam a inovação contínua para criar empresas extremamente bem-sucedidas. São Paulo: Leya, 2012.

SAVAGE, J. A criação da juventude: como o conceito de teenage revolucionou o século XX. Rio de Janeiro: Rocco, 2009.

SCHUMPETER, J. A teoria do desenvolvimento econômico. São Paulo: Nova Cultural, 1997.

SHUDSON, M. Descobrindo a notícia. Uma história social dos jornais nos Estados Unidos. Petrópolis: Vozes, 2010.

TAPSCOTT, D. A hora da geração digital. Como os jovens que cresceram usando a internet estão mudando tudo, das empresas aos governos. Rio de Janeiro: Agir, 2010.

ZAGO, G. S. Mídia, subjetivação e consumo de notícias em sites de redes sociais. Cadernos de Comunicação, Santa Maria, v. 17, n. 1, p. 309-324, 2013. Disponível em: <https://bit.ly/2L2TWCL>. Acesso em: 13 dez. 2017. 